\title{
Distribuição Espacial do Desempenho do Programa Bolsa Família: Um Estudo à Luz do IGD-M
}

\author{
Fábio Resende de Araújo ${ }^{1}$, Maria Arlete Duarte de Araújo², Fábia \\ Jaiany Viana de Souza ${ }^{3}$, Iris Linhares Pimenta Gurgel ${ }^{4}$, e Anna \\ Cecília Chaves Gomes ${ }^{5}$ \\ ${ }^{1}$ Universidade Federal do Rio Grande do Norte (UFRN), Natal, RN, Brasil (e-mail: \\ resende_araujo@hotmail.com); ${ }^{2}$ Universidade Pompeu Fabra, Barcelona, Espanha. (e-mail: \\ mariaarlete1956@gmail.com); ${ }^{3}$ Instituto Federal de Educação, Ciência e Tecnologia do Rio \\ Grande do Norte (IFRN), Natal, RN, Brasil (e-mail: fabiajaiany@yahoo.com.br); ${ }^{4}$ Universidade \\ Federal do Rio Grande do Norte (UFRN) Natal, RN, Brasil (e-mail: irislpimenta@gmail.com); \\ ${ }^{5}$ Universidade Federal do Rio Grande do Norte (UFRN), Natal, RN, Brasil (e-mail: \\ annacecilia.cg@gmail.com)
}

\section{INTRODUÇÃO}

onsiderado o carro-chefe da política de assistência social brasileira desde 2003, o Programa Bolsa Família (PBF) tem como objetivo principal o enfrentamento da fome e da miséria no país mediante a transferência direta de renda às famílias pobres. Ao mesmo tempo, o Programa pretende promover a emancipação social de seus beneficiários ao incentivar sua inserção no circuito de serviços básicos para o exercício da cidadania. A relevância do Programa é facilmente verificada pelo alcance de 13,8 milhões de famílias participantes ${ }^{1}$ que contabilizam mais de cinquenta milhões de beneficiários ( $1 / 4$ da população brasileira).

Com abrangência nacional, o PBF difere de outras políticas brasileiras pela relação de interdependência entre os entes que o desenvolvem (governos federal, estaduais e municipais), caracterizando-se por uma centralidade de concepção e comando das ações principais na União e as demais atividades (cadastros, transferência de benefício e acompanhamento das condicionalidades) nos governos locais ou subnacionais ${ }^{2}$. A forma como o PBF é executado ocorre de modo distinto de outras ações da área de assistência social no que diz respeito à centralização/descentralização das relações de governos envolvidos e os mecanismos usados para atingir seus objetivos (Bichir, 2011).

DADOS - Revista de Ciências Sociais, Rio de Janeiro, vol. 61, no-3, 2018, pp. 773 a 806.

http://dx.doi.org/10.1590/001152582018173 
A complexidade do Programa aumenta quando, além da perspectiva de descentralização de níveis de governo, também se pretende a integração de diferentes setores de atuação governamental. A descentralização horizontal ou intersetorialidade é também muitas vezes determinada pelas características de atuação do Programa, uma vez que o modelo de gestão federalizado resulta em distintas capacidades administrativas das localidades. A criação de competências e encargos para as esferas do governo e os setores de atuação do Programa tenta estabelecer tarefas e atribuições de papéis na execução da política e evidenciação de suas obrigações. A discussão da articulação intergovernamental não pode ser desatrelada da coordenação intersetorial do PBF.

O PBF apoia-se em uma rede de serviços previamente existentes: sistema de transferência de recursos (viabilizado pela Caixa Econômica Federal) e os sistemas públicos de educação, saúde e assistência social (Campelo, 2013). A inserção em uma rede já existente tem o intuito de fortalecê-lo e inserir principalmente os brasileiros que estão à margem do acesso a serviços e equipamentos públicos para promoção de cidadania. Portanto, o êxito do PBF é dependente da oferta desses serviços básicos. Entretanto, Cobo (2012) indica que muitos países que atualmente adotam Programas de Transferência de Renda Condicionada (PTRC) aos comprovadamente pobres não possuem capacidade financeira e administrativa para gerenciar sistemas complexos de controle de cumprimento de condicionalidades que são característicos desses programas. Tal acompanhamento esbarra na questão da oferta dos serviços, escolas, unidades de saúde, profissionais e transporte públicos que levam a uma precária operacionalização dessas atividades. Neste sentido, Pastorini (2006) aponta que as políticas focalizadas e centralizadas em governos nacionais tendem a ser frágeis quando se sustentam na estrutura pré-existente e deficitária das políticas universais que tencionam ser descentralizadas em governos locais, mas possuem grandes lacunas de assistência, principalmente no que diz respeito ao acesso equitativo dos mais pobres.

Um dos desafios na implementação do PBF de forma nacionalizada é a assimetria entre os governos locais, tornando imperativo que a coordenação federal do PBF formule uma estratégia para nivelar o desempenho de modo a transformar em potencialidades suas características específicas. O monitoramento e a avaliação da implementação do PBF se dá principalmente por meio do Índice de Gestão Descentralizada (IGD) nas versões municipal - IGD-M - e estadual -IGD-E. O IGD-M, 
por vigorar há mais tempo, é explorado pela literatura como indicador da eficácia da implementação do Programa nos municípios nos estudos de Monteiro, Ferreira e Teixeira (2009); Pedroso, Du Pin Calmon e Bandeira (2009); Monteiro (2008); Estrella e Ribeiro (2008); Pizzolato (2014); Araújo et. al (2015) e Monteiro, Silva e Ribeiro (2014).

O IGD é composto por uma fórmula que privilegia ações básicas do PBF. Por meio desse indicador é que são repassados os recursos de apoio à gestão do Programa. Dessa maneira, o IGD apresenta-se como um indicador passível de inferências diversas a respeito do PBF, podendo contribuir para a avaliação da eficácia do Programa não só de modo geral, como também de modo específico, uma vez que os subcomponentes do IGD são taxas relativas a processos básicos passíveis de isolamento.

Este estudo tem por objetivo compreender quais são os condicionantes da distribuição espacial do desempenho do PBF à luz do IGD-M nos municípios brasileiros. Para tanto, o artigo está estruturado em seis seções, incluindo esta Introdução. Na segunda seção, discorre-se sobre a avaliação institucional do PBF e o Índice de Gestão Descentralizada; na seção três, detalha-se a metodologia que explicita a seleção dos condicionantes da gestão do PBF em nível municipal. Como universo foram adotados todos os municípios brasileiros, delimitaram-se a variável dependente (IGD-M) e as variáveis independentes (Área territorial em km²; Percentual de população urbana; Densidade de Beneficiários na localidade expressado em famílias por $\mathrm{km}^{2}$; Número de Famílias por Unidade do Programa Saúde da Família; Número de Famílias por Centro de Referência da Assistência Social e Número de Famílias por escola de ensino fundamental). A seção quatro trata dos resultados do estudo evidenciando correlações negativas entre o desempenho do PBF em localidades com maior área territorial, regiões urbanas e com maior densidade de beneficiários. São apresentados dados do modelo de regressão múltipla elaborado para explicar o desempenho do IGD-M nos municípios brasileiros. A última seção apresenta as principais conclusões sobre a necessidade de pensar o programa de modo estratégico, compreendendo a diversidades das localidades onde este ocorre.

\section{AVALIAÇÃO INSTITUCIONAL DO PBF: ÍNDICE DE GESTÃO DESCENTRALIZADA (IGD)}

A atual forma de avaliação e monitoramento do PBF se dá pelo Índice de Gestão Descentralizada (IGD), instituído pela Portaria GM/MDS no 
148/2006, que permite a mensuração da qualidade da gestão municipal por meio do respectivo desempenho no cadastramento e acompanhamento das condicionalidades. Em outras palavras, o IGD serve tanto para medir a implementação das ações básicas do Programa, como para incentivar os municípios a obterem cada vez mais recursos financeiros para apoio à gestão.

A transferência dos recursos aos municípios é feita desde que sejam alcançados os padrões mínimos de gestão desse indicador, o que o caracteriza como uma avaliação de processo que procura estimar de forma integrada a eficácia do arranjo de ações realizadas pelo Programa em Estados e Municípios. O IGD (nas suas variações de IGD-M para Municípios e IGD -E para Estados) visa estimular bons procedimentos no Programa, pois se trata de um indicador de desempenho transparente (Cadastro, Atualização de Cadastro e as Condicionalidades da Educação e da Saúde). Variando entre 0 e 1 , resulta em um recurso que é proporcional ao número de famílias participantes naquela localidade (Ministério de Desenvolvimento Social e Combate à Fome, 2012).

O IGD-M atualmente é calculado por meio de uma fórmula que envolve quatro fatores. Além do fator de operação (Fator I), para o qual serão feitas maiores considerações adiante, há outros três fatores (II, III, IV) que funcionam como condicionadores do repasse de recursos, a saber:

- Fator II de Adesão ao Sistema Único de Assistência Social (SUAS)

- Fator III Apresentação da comprovação de gastos dos recursos do IGD

- Fator IV Aprovação total da comprovação de gastos dos recursos do IGD pelo Conselho Municipal de Assistência Social

Esses outros três fatores representam 0 ou 1 na fórmula abaixo e indicam se o município aderiu ao Sistema Único de Assistência Social (SUAS), fez comprovação do gasto do recurso do IGD e se consta informação sobre aprovação pelo Conselho Municipal de Assistência Social.

IGD-M = Fator $1 \times$ Fator $2 \times$ Fator $3 \times$ Fator 4

Valor a ser transferido $=($ IGD-M $\times \mathrm{R} \$ 3,50 \times$ por cadastro válido atualizado $\left.^{3}\right)+$ incentivos

O principal componente do IGD é o Fator de Operação (ou Fator 1). Trata-se da representação unificada de variáveis-síntese dos processos restritos à gestão municipal do Programa, sendo este formado por qua- 
tro subindicadores que explicitam funções básicas: Cobertura do cadastro único, Atualização do cadastro único, Condicionalidade da Educação e Condicionalidade da Saúde (Ministério de Desenvolvimento Social e Combate à Fome, 2012). Até 2009, antes do acréscimo dos outros fatores, o Fator de Operação era designado como o próprio IGD.

A cobertura do cadastro único trata do número de inscritos no cadastro do Programa que possuem perfil de renda per capita em situação de pobreza e pobreza extrema no município, considerando os dados do Censo mais atual do Instituto Brasileiro de Geografia e Estatística (IBGE). O percentual de alcance desse cadastro do total das famílias nessa condição nos municípios representa um dos subindicadores do IGD total. No índice, esse processo é representado pela Taxa de Cobertura Qualificada de Cadastros (TCQC) calculada conforme abaixo:

$\mathrm{TCQC}=\frac{\text { Número de cadastros válidos de famílias com perfil Cadastro Único no município }}{\text { Número de famílias estimadas como público alvo do Cadastro Único no Município pelo IBGE }}$

Aatualização de cadastro é um procedimento que verifica se os beneficiários ainda se encontram na condição de vulnerabilidade de renda que os possibilitou entrar no programa. Os agentes municipais, segundo a legislação do programa, a cada dois anos devem visitar as famílias. O cruzamento de bancos de dados do Ministério do Trabalho também é usado para verificar a focalização do programa. No Fator de Operação esse processo é representado pela Taxa de Atualização Cadastral (TAC) calculada pela divisão:

$T A C=\frac{\text { Número de cadastros válidos de famílias com perfil Cadastro Único no município atualizados }}{\text { Número de cadastros válidos com perfil Cadastro Único no município }}$

O cumprimento dos objetivos das condicionalidades e a gestão de cadastros são o principal foco de avaliação do PBF. As condicionalidades da educação objetivam que todas as crianças e adolescentes entre 6 e 15 anos devem estar devidamente matriculadas e com frequência escolar mensal mínima de $85 \%$ da carga horária. Já os estudantes entre 16 e 17 anos devem ter frequência de, no mínimo, 75\%. A Taxa de Acompanhamento da Frequência Escolar (TAFE) compõe o Fator I e é calculada por meio da seguinte divisão:

$$
T A F E=\frac{\text { Número de crianças e adolescentes com informações de frequência }}{\text { Número }}
$$


A avaliação do cumprimento das condicionalidades da saúde se realiza pelo acompanhamento semestral das famílias nos estabelecimentos de saúde, quanto à imunização das crianças, realização do pré-natal das gestantes e exame de antropometria (mensuração de peso e altu$\mathrm{ra} /$ comprimento) a fim de monitorar o estado nutricional das pessoas e verificar em que medida a insegurança alimentar grave está sendo combatida. No Fator de Operação, esse monitoramento é representado pela Taxa de Acompanhamento da Agenda de Saúde (TAAS) calculada por meio de:

$T A A S=\frac{\text { Número de famílias beneficiárias com perfil saúde com informações de acompanhamento }}{\text { Número total de famílias com perfil saúde no município }}$

Compondo $50 \%$ do Fator de Operação do IGD, o cumprimento das condicionalidades é visto como ponto determinante na implementação do programa. Apesar da sua composição, não há nessas subtaxas do Fator de Operação nenhum aspecto de avaliação da qualidade dos serviços. A composição do IGD não escapa ao debate sobre as contrapartidas. OQuadro 1 resume os principais componentes da formula do IGD-M.

O IGD-M pode não ser repassado aos municípios com fraco desempenho nas taxas do Fator de Operação ou descumprimento de itens obrigatórios. Como condição básica para recebimento do recurso faz-se necessário atingir os valores mínimos de 0,20 para cada uma das taxas do Fator de Operação (Fator 1) e 0,55 no Fator de Operação, ou seja, após o cálculo, a média aritmética das taxas deve atingir um valor $=0,55$. O repasse financeiro prevê incentivos às boas práticas de gestão como incremento de $10 \%$ do valor final dos recursos, caso os municípios comprovem o cumprimento das condutas previamente estabelecidas, como detalha o Quadro 2.

O IGD-M possui uma representatividade da implementação dos procedimentos básicos do PBF, pois trata-se de um indicador de eficácia, evidenciando o nível de cumprimento de atividades fundamentais do programa. Pelas características citadas, o IGD-M é um preditor de desempenho das atividades do PBF e uma variável que pode ser problematizada a fim de identificar os possíveis determinantes da gestão do programa. Os estudos que aprofundam a discussão sobre a avaliação e o monitoramento do programa do PBF são descritos no Quadro 3 e têm o IGD-M como ponto principal de análise. 
Distribuição Espacial do Desempenho do Programa Bolsa Família

Quadro 1

Principais Componentes da Fórmula do IGD-M.

\begin{tabular}{|l|l|}
\hline & COMPONENTES DA FORMULA DO IGD-M \\
\hline Formula & IGD-M = Fator I x Fator I X Fator III x Fator IV \\
\hline $\begin{array}{l}\text { Fator de Operação } \\
\text { (Fator 1) }\end{array}$ & $\begin{array}{l}\text { Corresponde à média aritmética simples da TCQC, TAC, TAFE, } \\
\text { TAAS }\end{array}$ \\
\hline $\begin{array}{l}\text { TCQC - Taxa de } \\
\text { Cobertura } \\
\text { Qualificada de } \\
\text { Cadastros }\end{array}$ & $\begin{array}{l}\text { Calculada pela divisão do número de cadastros válidos de famí- } \\
\text { lias com perfil Cadastro Único, no município, pela quantidade de } \\
\text { famílias estimadas como público alvo do Cadastro Único no Mu- } \\
\text { nicípio. }\end{array}$ \\
\hline $\begin{array}{l}\text { TAC - Taxa de } \\
\text { Atualização } \\
\text { Cadastral }\end{array}$ & $\begin{array}{l}\text { Calculada pela divisão do número de cadastros válidos de famí- } \\
\text { lias com perfil Cadastro Único no município atualizados nos últi- } \\
\text { mos dois anos, pelo número de cadastros válidos com perfil Ca- } \\
\text { dastro Único no município }\end{array}$ \\
\hline $\begin{array}{l}\text { TAFE - Taxa de } \\
\text { Acompanhamento } \\
\text { da Frequência } \\
\text { Escolar }\end{array}$ & $\begin{array}{l}\text { Calculada pela divisão do número de crianças e adolescentes per- } \\
\text { tencentes às famílias beneficiárias do PBF no município, com in- } \\
\text { formações de frequência escolar, pelo número total de crianças e } \\
\text { adolescentes pertencentes a famílias beneficiárias do PBF no mu- } \\
\text { nicípio. }\end{array}$ \\
\hline $\begin{array}{l}\text { TAAS - Taxa de } \\
\text { Acompanhamento } \\
\text { da Agenda de } \\
\text { Saúde }\end{array}$ & $\begin{array}{l}\text { Calculada pela divisão do número de famílias beneficiárias com } \\
\text { perfil saúde no município com informações de acompanhamento } \\
\text { de condicionalidades de saúde, pelo número total de famílias com } \\
\text { perfil saúde no município }\end{array}$ \\
\hline Fator II & $\begin{array}{l}\text { Fator de adesão ao Sistema Único de Assistência Social (SUAS). } \\
\text { Indica se o município aderiu ao SUAS, de acordo com a Norma } \\
\text { Operacional Básica (NOB /SUAS); }\end{array}$ \\
\hline Fator IV & $\begin{array}{l}\text { Fator de informação da apresentação da comprovação de gastos } \\
\text { dos recursos do IGD-M. Indica se o gestor do FMAS lançou no sis- } \\
\text { tema informatizado do MDS (SuasWeb) a comprovação de gastos } \\
\text { ao Conselho Municipal de Assistência Social. }\end{array}$ \\
\hline $\begin{array}{l}\text { Fator de informação da aprovação total da comprovação de gastos } \\
\text { dos recursos do IGD-M pelo CMAS. Indica se o referido Conselho } \\
\text { registrou no SuasWeb a aprovação integral das contas apresenta- } \\
\text { das pelo gestor do FMAS. }\end{array}$ \\
\hline Fator
\end{tabular}

Fonte: Elaborado pelos autores (2017) a partir de Ministério do Desenvolvimento Social e Combate a Fome (2012)

Nos trabalhos que tratam deste tema um resultado é recorrente: o número das famílias assistidas pelo programa municípios pode ter implicação para o desempenho das atividades do programa. Pizzolato (2014) identificou que municípios com menor número de beneficiários tinham melhor desempenho no IGD-M. Monteiro, Ferreira e Teixeira (2009) indicam também a existência de relação negativa entre o aumento da população e das famílias beneficiadas e o IGD-M, concluindo que 


\section{Quadro 2}

Detalhamento dos Incentivos Adicionais do IGD-M

\begin{tabular}{|c|c|}
\hline INCENTIVO & DETALHAMENTO \\
\hline $\begin{array}{l}\text { INCENTIVO I- } 3 \% \text { (três por cen- } \\
\text { to) proporcionais ao acompa- } \\
\text { nhamento das famílias benefi- } \\
\text { ciárias em situação de descum- } \\
\text { primento de condicionalidades } \\
\text { que estejam em processo de } \\
\text { acompanhamento familiar; }\end{array}$ & $\begin{array}{l}\text { Processo de acompanhamento familiar: consideram-se as } \\
\text { famílias beneficiárias registradas em sistema de condi- } \\
\text { cionalidades (Sicon) monitoradas por meio das ações } \\
\text { sócio-assistenciais realizadas no âmbito do Sistema } \\
\text { Único de Assistência Social (SUAS), por intermédio } \\
\text { dos Centros de Referência de Assistência Social } \\
\text { (CRAS), dos Centros de Referência Especializada em } \\
\text { Assistência Social (CREAS) ou das equipes de assistên- } \\
\text { cia social dos municípios; e de ações realizadas no âm- } \\
\text { bito de outras políticas sociais, conforme legislação es- } \\
\text { pecífica }\end{array}$ \\
\hline
\end{tabular}

INCENTIVO II - 3\% (três por Apuração de eventuais irregularidades: relativas aos relacento) quando o município tórios dos órgãos de controle, como Tribunais de Conatender, nos prazos estipula- tas, Controladoria Geral da União (CGU), bem como dos, demandas da Senarc refe- aos documentos expedidos pelo MDS para providênrentes à apuração de eventuais cias de averiguação pelos gestores municipais; irregularidades na execução local do PBF;

INCENTIVO III - 2\% (dois por Dados referentes à Gestão Municipal: relativos ao prefeicento) quando o município tiver to e à prefeitura municipal; ao gestor do PBF e à sua $100 \%$ (cem por cento) dos dados equipe de Gestão; e à instância municipal de controle referentes à Gestão Municipal social responsável pelo acompanhamento do PBF e aos atualizados no Sistema de Ges- seus componentes e ao CMAS e seus componentes. tão do PBF (SIGPBF) há menos de um ano;

INCENTIVO IV - 2\% (dois por Cartões entregues: considera-se o número de cartões cento) quando o município emitidos até 60 (sessenta) dias antes da data de apuraapresentar pelo menos 96\% (no- ção do IGD-M e o número de cartões cancelados.

venta e seis por cento) de car-

tões do PBF entregues na data

de apuração do IGD-M

Fonte: Elaborado pelos autores (2017) a partir de Ministério do Desenvolvimento Social e Combate a Fome (2012)

municípios maiores apresentam menores escores de IGD dado que possuem a menor relação de demanda e assistência (assistência relativa). Estrella e Ribeiro (2008) tentando esclarecer essa relação inversamente proporcional entre demanda e desempenho, também encontrada no seu estudo, indicam que a melhor qualidade na prestação da informação ocorre justamente nos municípios com indicadores sociais mais frágeis, que são os mais dependentes dos recursos do PBF, mas os que apresentam menor demanda relativa. 
Distribuição Espacial do Desempenho do Programa Bolsa Família

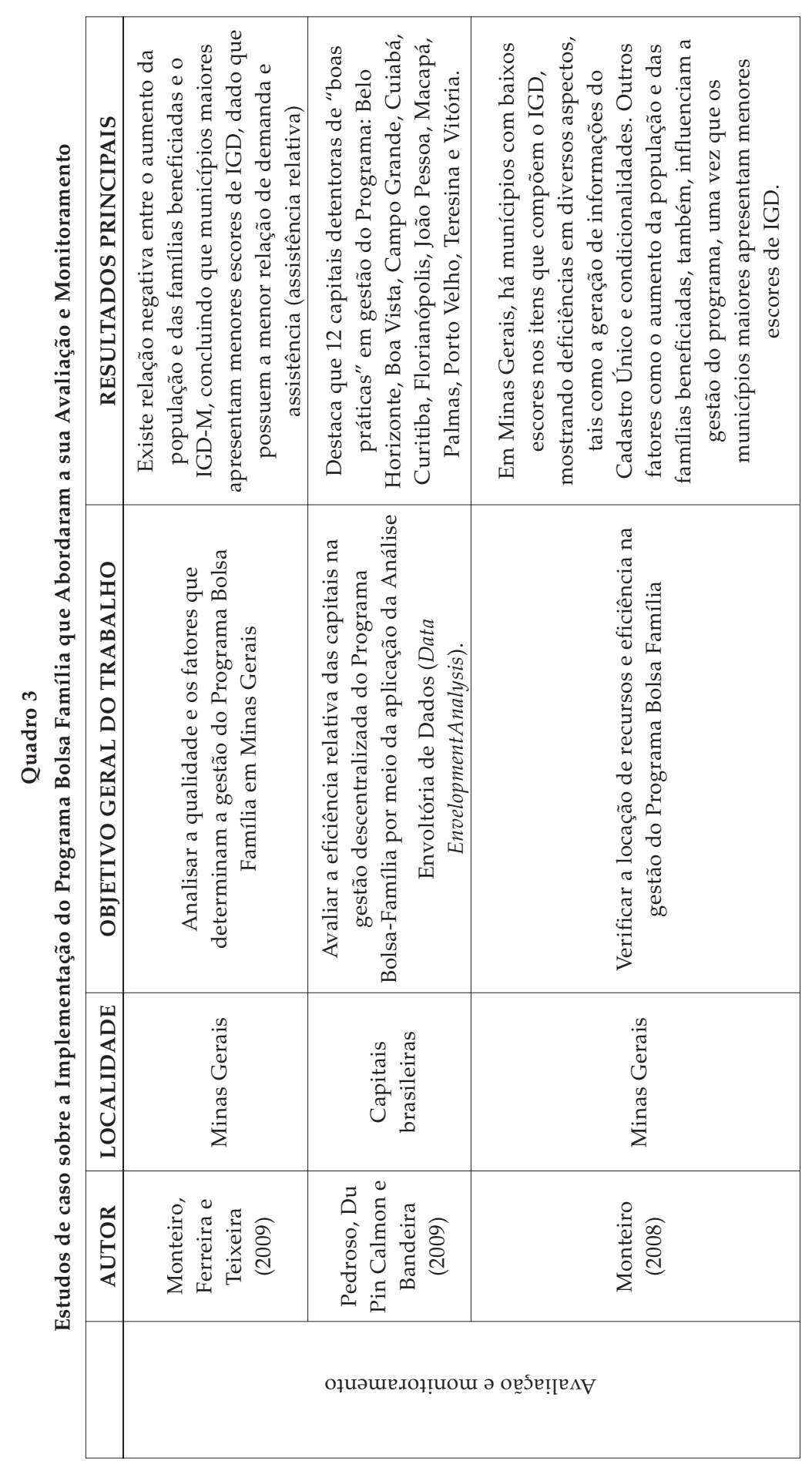

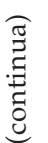

DADOS - Revista de Ciências Sociais, Rio de Janeiro, vol. 61, nํㅜ, 2018 
Fábio R. Araújo, Maria A.D. Araújo, Fábia J.V. Souza, Iris L.P. Gurgel, e Anna C.C. Gomes



782 DADOS - Revista de Ciências Sociais, Rio de Janeiro, vol. 61, n 3, 2018 
Os menores municípios não são dependentes de uma rede estruturada de assistência porque a demanda é pequena, o que os levam a melhores indicadores de gestão. Mesmo tendo as piores condições de renda possuem uma rede de assistência que (mesmo que pequena em termos absolutos) consegue implementar os acompanhamentos básicos com as famílias. O raciocínio é que os grandes municípios, de maior renda, apesar de uma rede maior (em termos absolutos, não relativos, ou seja, mais famílias por equipamentos de assistência) não garantem um bom monitoramento porque a demanda das famílias é muito alta.

Pode-se observar que a as análises se concentram no comportamento dos indicadores do Fator de Operação (principal componente do IGD), com o número de beneficiários indicando uma gestão mais complexa (devido a menores índices de desempenho do programa) em localidades com maior demanda. Os estudos reforçam a ideia de que o programa possui diferente implementação entre as localidades com perfis diferentes e que há necessidade de aprofundar os estudos que visem revelar os fatores que facilitam ou dificultam a gestão do Programa e, por conseguinte, seu desempenho. Com base nessa constatação, este artigo pretende estudar os condicionantes que podem agravar o desempenho da gestão do PBF principalmente nas regiões de grande demanda.

\section{METODOLOGIA}

Este estudo aprofunda a discussão sobre a descentralização da gestão PBF, em especial sobre a relação entre a distribuição espacial da demanda e a rede de assistência dos sistemas de serviços básicos onde o Programa opera. O fato do PBF ser um Programa normatizado pelo Governo Federal e executado pelos governos subnacionais (estados e municípios) pode causar uma padronização de condutas gerenciais não compatível com a heterogeneidade dos municípios brasileiros. Para observar tais variações entre regiões, estados e municípios, optou-se por trabalhar com dados de todos os 5.561 municípios do Brasil, tendo sido selecionados para análise aqueles que apresentavam as informações necessárias à realização da pesquisa nos bancos de dados utilizados para a coleta.

Entende-se que o desempenho do IGD-M, assim como de seus subcomponentes, expressa o grau de atendimento da implementação do Programa naquela localidade, traduzindo assim a eficácia da gestão. O es-

DADOS - Revista de Ciências Sociais, Rio de Janeiro, vol. 61, n 3, 2018 
tudo considerou como variável dependente - o Fator de Operação do IGD-M, principal indicador da gestão do Programa, o qual corresponde à média aritmética simples de outras quatro (4) taxas ${ }^{4}$ de processos fundamentais do PBF. Foram considerados possíveis condicionadores da gestão do Programa e, para efeito da pesquisa, usados como variáveis independentes: Área territorial em $\mathrm{km}^{2}$; Percentual de população urbana; Densidade Populacional de Beneficiários na localidade (famílias por $\mathrm{km}^{2}$ ); Número de Famílias beneficiárias por Unidade do PSF; Número de Famílias beneficiárias por CRAS/CREAS; e o Número de Famílias beneficiárias por escola de ensino fundamental.

O Quadro 4 explicita a variável dependente (IGD-M), as variáveis independentes e as hipóteses do estudo.

De acordo com os estudos de Monteiro, Ferreira e Teixeira (2009), Pedroso, Du Pin Calmon e Bandeira (2009), Monteiro (2008), Estrella e Ribeiro (2008), Pizzolato (2014) e Monteiro, Silva e Ribeiro (2014) há uma correlação negativa entre os melhores indicadores de desempenho do IGD-M e o número de beneficiários dos municípios. Considerando este fato, algumas análises foram realizadas considerando também os dados isolados das capitais brasileiras separadas por regiões.

Os dados sobre os municípios da região foram obtidos por meio de bancos de dados das páginas oficiais do MDS, IBGE, DATASUS, MEC e SAGI. A utilização de algumas variáveis em números absolutos poderia levar a uma interpretação equivocada. Portanto, alguns indicadores são na verdade taxas, onde o numerador é o número de famílias de cada município. Dessa forma, procurou-se evidenciar o caráter relativo dos dados em relação à demanda de beneficiários daquela localidade, não os tratando em termos absolutos. Esses indicadores foram: Densidade de Beneficiários na localidade (famílias por $\mathrm{Km}^{2}$ ); Número de Famílias por Unidade do Programa Saúde da Família (PSF); Número de Famílias por CRAS e CREAS e Número de Famílias por escola de ensino fundamental.

Os dados utilizados do IGD-M têm como referência o período de dezembro de 2012 e foram obtidos através do site da Secretaria de Avaliação e Gestão da Informação através da Matriz Informação Social versão 1.5. As informações do IBGE (Área territorial em km² e Percentual de população urbana) foram extraídas do Censo 2010. O número de Equipes de Saúde da Família por municípios da Região Nordeste foi retirado dos dados do Ministério da Saúde e tabulado por intermédio 
Distribuição Espacial do Desempenho do Programa Bolsa Família

Quadro 4

Resumo das Hipóteses do Estudo

\begin{tabular}{|c|c|c|}
\hline $\begin{array}{c}\text { VARIÁVEL } \\
\text { DEPENDENTE }\end{array}$ & $\begin{array}{l}\text { VARIÁVEIS } \\
\text { INDEPENDETES }\end{array}$ & HIPÓTESES \\
\hline \multirow{6}{*}{  } & $\begin{array}{c}\text { Área territorial em } \\
\mathrm{km}^{2}\end{array}$ & $\begin{array}{l}\text { Existe uma relação negativa entre o } \\
\text { desempenho do IGD e de seus componentes } \\
\text { e o tamanho dos municípios e estados. }\end{array}$ \\
\hline & $\begin{array}{c}\text { Percentual de } \\
\text { população urbana }\end{array}$ & $\begin{array}{l}\text { Localidades com maior percentual de } \\
\text { população urbana têm uma relação negativa } \\
\text { com bons indicadores do IGD e seus } \\
\text { subcomponentes. }\end{array}$ \\
\hline & $\begin{array}{c}\text { Densidade de } \\
\text { Beneficiários na } \\
\text { localidade } \\
\left(\text { famílias por } \mathrm{km}^{2} \text { ) }\right.\end{array}$ & $\begin{array}{l}\text { Supõe-se que existe uma relação negativa } \\
\text { entre as localidades com maior concentração } \\
\text { de famílias beneficiárias e o IGD e seus } \\
\text { subcomponentes. }\end{array}$ \\
\hline & $\begin{array}{l}\text { Número de } \\
\text { Famílias por } \\
\text { Unidade do } \\
\text { Programa Saúde } \\
\text { da Família (PSF) }\end{array}$ & $\begin{array}{l}\text { Acredita-se que as localidades que tenham } \\
\text { um maior número de Equipes do PSF por } \\
\text { beneficiários possuam melhor desempenho } \\
\text { na TAAS e consequentemente no fator de } \\
\text { operação do IGD, estabelecendo uma } \\
\text { relação negativa entre estas variáveis }\end{array}$ \\
\hline & $\begin{array}{c}\text { Número de } \\
\text { Famílias por CRAS } \\
\text { e CREAS }\end{array}$ & $\begin{array}{l}\text { É suposto uma relação negativa entre um } \\
\text { maior número de famílias por unidade de } \\
\text { CRAS e o desempenho do IGD, especial dos } \\
\text { componentes ligados ao cadastro e } \\
\text { atualização deste, a TCQC e a TAC } \\
\text { respectivamente. }\end{array}$ \\
\hline & $\begin{array}{c}\text { Número de } \\
\text { Famílias por escola } \\
\text { de ensino } \\
\text { fundamental }\end{array}$ & $\begin{array}{l}\text { Um maior número de famílias por escolas de } \\
\text { ensino fundamental pública torna menos } \\
\text { efetivo o acompanhamento das } \\
\text { condicionalidades da educação que se } \\
\text { expressa na TAFE e consequentemente tem } \\
\text { uma relação negativa com melhores } \\
\text { indicadores de IGD }\end{array}$ \\
\hline
\end{tabular}

Fonte: Elaboração dos autores (2017).

do TabWin do DATASUS; a fonte foi o Cadastro Nacional de Estabelecimentos de Saúde de dezembro de 2012. O número de Escolas Públicas de Ensino fundamental por município foi obtido no Censo Escolar 2012 do MEC. O detalhamento das variáveis utilizadas e sua obtenção encontram-se no Quadro 5.

Os dados obtidos em abril de 2017 foram digitados e armazenados no programa Microsoft Excel versão 2010. O banco de dados foi exporta- 
Fábio R. Araújo, Maria A.D. Araújo, Fábia J.V. Souza, Iris L.P. Gurgel, e Anna C.C. Gomes

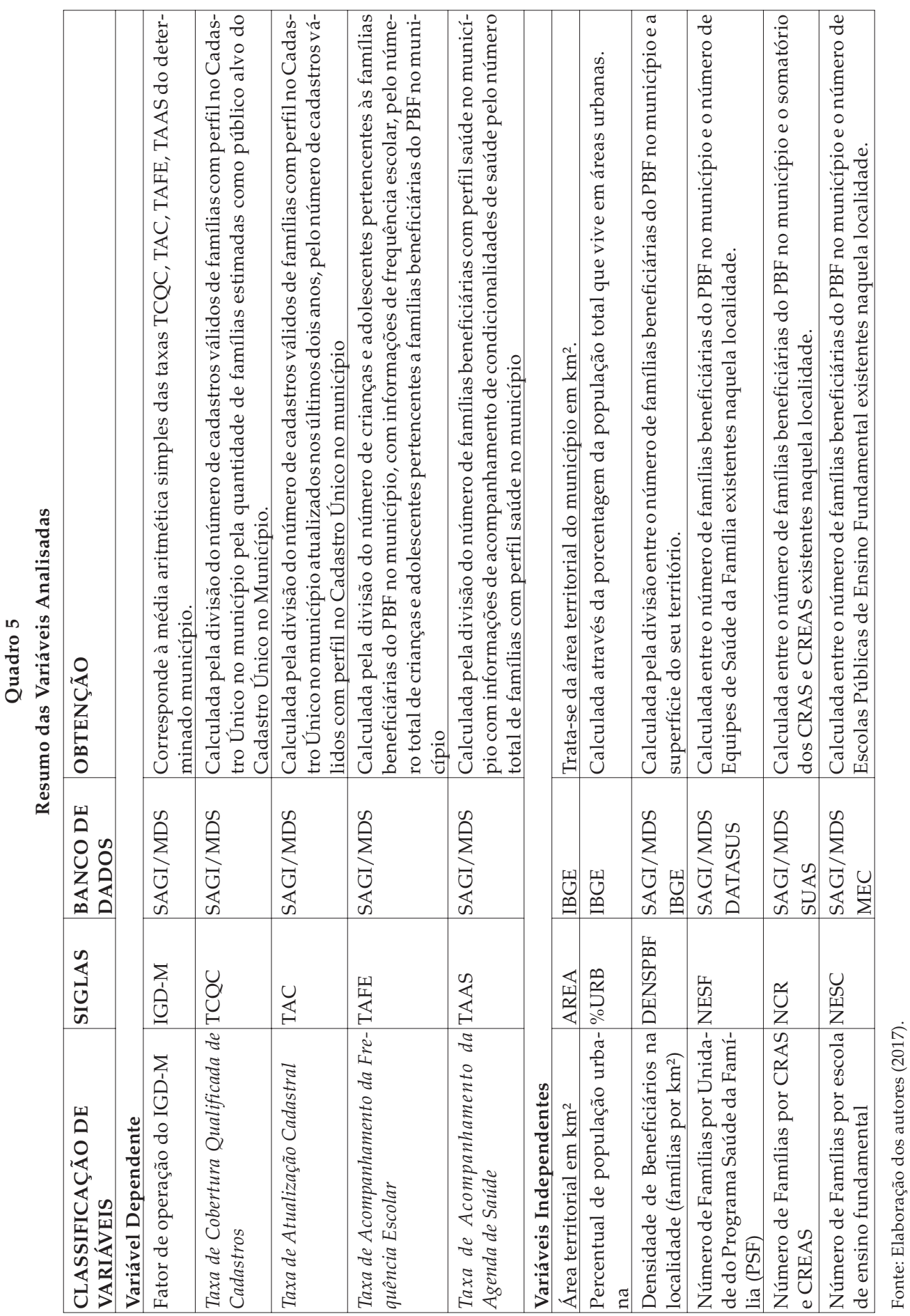

786 DADOS - Revista de Ciências Sociais, Rio de Janeiro, vol. 61, ํㅜ 3, 2018 
do para o software R versão 2.15.1, o qual foi utilizado neste trabalho como uma das ferramentas para análises estatísticas. No teste das hipóteses, usamos o coeficiente de Correlação de Pearson para medir o relacionamento linear entre duas variáveis. Para a construção do modelo de regressão múltipla, realizado pelo EViews 9.5 Statistic, utilizamos as variáveis que tinham significância estatística no relacionamento com a variável independente.

\section{DISCUSSÃO DOS DADOS}

A distribuição de famílias beneficiárias do PBF nas regiões do Brasil em ordem decrescente é a seguinte: Nordeste (50,4\%), Sudeste (25,3\%), Norte (11,4\%), Sul (7,5\%), Centro-Oeste (5,4\%), segundo dados obtidos por Camargo et al. (2013) elaborado a partir da Folha de pagamento do PBF (SENARC/MDS). A espacialidade da demanda do programa pode ser melhor entendida no mapa da ilustração 1 que apresenta o percentual de famílias atendidas pelo PBF nos domicílios apurados pelo Censo (2010), segundo Unidades da Federação. O Nordeste se destaca pelos elevados percentuais da população beneficiária.

Figura 1

Famílias Atendidas pelo PBF entre o Total de Domicílios Apurados pelo Censo (2010), Segundo Unidades da Federação (março de 2013)

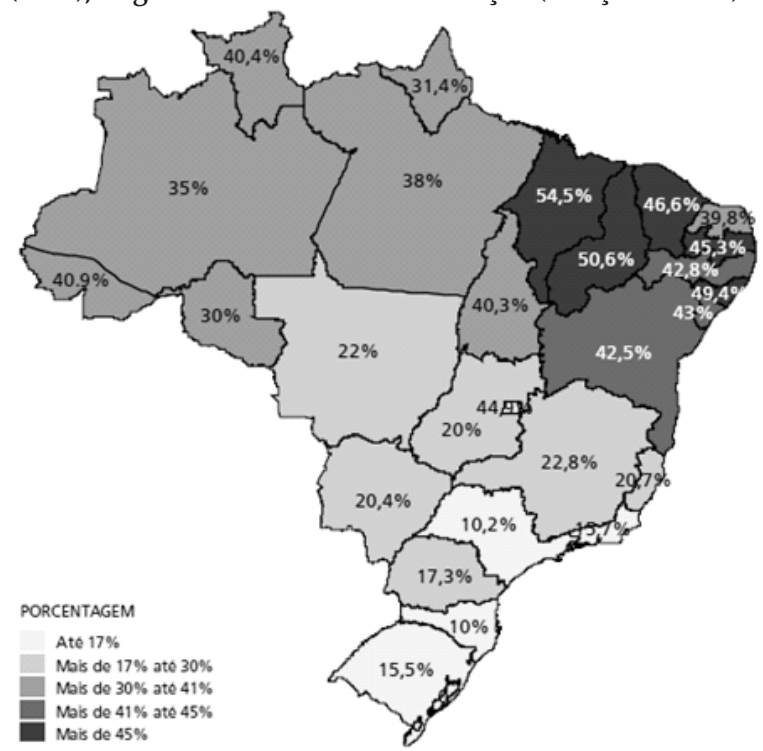

Fonte: SENARC/MDS, A partir dos microdados do Cadúnico (SENARC/MDS) de fevereiro de 2013 e do Censo 2010 (IBGE).

DADOS - Revista de Ciências Sociais, Rio de Janeiro, vol. 61, n 3, 2018 
O PBF apresenta diferentes níveis de implementação no Brasil, de acordo com a região, conforme apresenta a Tabela 1 . Na média nacional, $\mathrm{o}$ Programa apresentou em dezembro de 2012 um Fator de Operação 0,86 . Entre os componentes, com menores desempenhos em todas as regiões, estão a atualização cadastral (TAC) e o Acompanhamento da Agenda Saúde (TAAS).

Tabela 1

Distribuição dos valores do Índice de Gestão Descentralizada por Regiões em Dezembro de 2012

\begin{tabular}{|c|c|c|c|c|c|}
\hline \multicolumn{6}{|c|}{$\begin{array}{l}\text { INDICE DE GESTÃO DESCENTRALIZADA DAS REGIÕES } \\
\text {-Fator de Operação IGD-M }\end{array}$} \\
\hline \multirow[t]{2}{*}{ Região } & \multicolumn{2}{|c|}{ Condicionalidades } & \multicolumn{2}{|c|}{ Cadastro } & $\begin{array}{c}\text { Fator de } \\
\text { Operação } \\
\text { IGD-M }\end{array}$ \\
\hline & $\begin{array}{c}\text { Taxa de } \\
\text { Acompa- } \\
\text { nhamento } \\
\text { da Fre- } \\
\text { quência } \\
\text { Escolar } \\
\text { (TAFE) }\end{array}$ & $\begin{array}{c}\text { Taxa de } \\
\text { Acompanha- } \\
\text { mento da } \\
\text { Agenda de } \\
\text { Saúde } \\
\text { (TAAS) }\end{array}$ & $\begin{array}{c}\text { Taxa de } \\
\text { Atualização } \\
\text { Cadastral } \\
\text { (TAC) }\end{array}$ & $\begin{array}{c}\text { Taxa de } \\
\text { Cobertura } \\
\text { Qualificada de } \\
\text { Cadastros } \\
\text { (TCQC) }\end{array}$ & Geral \\
\hline Brasil & 0,89 & 0,80 & 0,76 & 0,98 & 0,86 \\
\hline Norte & 0,87 & 0,76 & 0,79 & 0,97 & 0,85 \\
\hline Nordeste & 0,90 & 0,84 & 0,79 & 1,00 & 0,88 \\
\hline Centro-oeste & 0,86 & 0,76 & 0,74 & 0,97 & 0,84 \\
\hline Sudeste & 0,89 & 0,78 & 0,74 & 0,97 & 0,85 \\
\hline Sul & 0,90 & 0,81 & 0,74 & 0,96 & 0,86 \\
\hline
\end{tabular}

Fonte: Elaboração dos autores (2016) através dos dados do MDS de dezembro de 2012

As capitais brasileiras possuem peculiaridades, pois são cidades com expressivo número de beneficiários no Brasil, o que pode tornar mais complexa a do Programa. Como se pode observar na Tabela 02, a média do Fator de Operação do IGD-M das capitais $(0,79)$ é inferior à média dos seus Estados $(0,86)$. A subtaxa que mais contribui para essa diferença é a TAAS, que indica o monitoramento da saúde dos beneficiários. Na média nacional, essa taxa é de 0,80 e nas capitais é de 0,62 . Essa condicionalidade exige maior capacidade técnica das equipes para localizar e acompanhar as famílias, e esse conjunto de tarefas é mais difícil de realizar nas áreas metropolitanas. 
Distribuição Espacial do Desempenho do Programa Bolsa Família

Tabela 2

Fator de Operação do Índice de Gestão Descentralizada (IGD-M) nos Municípios Brasileiros, Dezembro de 2012

\begin{tabular}{c|c|c|c|c|c|c}
\hline \multicolumn{7}{c}{ MÉDIA DOS MUNCIPIOS DA REGIÃO } \\
\hline MUNICÍPIOS DAS REGIÕES & NO & NE & CO & SE & SU & BRA \\
\hline IGD-M Fator de Operação & 0,85 & 0,88 & 0,84 & 0,85 & 0,86 & 0,86 \\
\hline TCQC & 0,97 & 1,00 & 0,97 & 0,97 & 0,96 & 0,98 \\
\hline TAC & 0,79 & 0,79 & 0,74 & 0,74 & 0,74 & 0,76 \\
\hline TAAS & 0,76 & 0,84 & 0,76 & 0,78 & 0,81 & 0,80 \\
\hline TAFE & 0,87 & 0,90 & 0,86 & 0,89 & 0,90 & 0,89 \\
\hline CAPITAIS DAS REGIÕES & NO & NE & CO & SE & SU & BRA \\
\hline IGD-M Fator de Operação & 0,81 & 0,77 & 0,82 & 0,78 & 0,83 & 0,79 \\
\hline TCQC & 0,96 & 1,00 & 1,00 & 0,88 & 1,00 & 0,97 \\
\hline TAC & 0,69 & 0,74 & 0,73 & 0,70 & 0,74 & 0,72 \\
\hline TAAS & 0,68 & 0,53 & 0,66 & 0,66 & 0,66 & 0,62 \\
\hline
\end{tabular}

Legenda: Taxa de Cobertura Qualificada de Cadastros (TCQC), Taxa de Atualização Cadastral (TAC), Taxa de Acompanhamento da Agenda de Saúde (TAAS), Taxa de Acompanhamento da Frequência Escolar (TAFE)

Fonte: Elaboração dos autores (2016) através dos dados do MDS de dezembro 2012

Sobre o baixo desempenho do acompanhamento da agenda da saúde em relação aos demais indiciadores do Programa, Estrella e Ribeiro (2008) afirmam que parte da inoperância da condicionalidade da saúde está no envio de informações do Sistema de Vigilância Alimentar e Nutricional -Módulo Bolsa Família (SISVAN), sistema responsável pela consolidação das informações da condicionalidade. O envio das informações de fluxo semestral é dificultado pelo perfil das famílias mais vulneráveis que não possuem casa própria e mudam muito de endereço, Além disso, o fluxo de informação com entraves intermediários entre a coleta de informações nas unidades de saúde e as centrais de envio de informações online devido à não informatização das unidades de saúde, aumenta as possibilidades de fraudes, sub-registros, pouca agilidade no envio e baixa integração da condicionalidade com o Cadastro Único (CADUNICO)

Entre as hipóteses do presente estudo aponta-se que um dos possíveis condicionantes para a gestão do PBF é o tamanho da área geográfica das localidades. Conforme mostra a Tabela 3, existe de fato uma correlação negativa entre a área territorial dos municípios e o Fator de Ope-

DADOS - Revista de Ciências Sociais, Rio de Janeiro, vol. 61, n 3, 2018 
ração do IGD-M, que é significativa. Entre os indicadores que compõem o IGD-M, as subtaxas TAFE (Acompanhamento da frequência escolar), TCQC (Cobertura atualizada de cadastros) e TAC (Atualização Cadastral) apresentaram correlação negativa com o tamanho dos municípios com significância estatística. A TAAS (Acompanhamento da saúde) apresentou relação negativa com o tamanho dos municípios, mas sem significância estatística.

Tabela 3

Correlação do IGD-M e seus Subcomponentes e a Área Territorial dos Municípios da Região nos Municípios Brasileiros Dezembro de 2012

\begin{tabular}{l|c|c|c|c|c}
\hline \multicolumn{7}{c}{ CORREAÇÃO DE PEARSON } \\
\hline & IGD fator 1 & TAFE & TAAS & TCQC & TAC \\
\hline Área Territorial dos Municípios & $-0,076$ & $-0,054$ & $-0,008$ & $-0,035$ & 0,042 \\
\hline \multicolumn{7}{|c}{ Valor-p } \\
\hline & IGD fator 1 & TAFE & TAAS & TCQC & TAC \\
\hline Área Territorial dos Municípios & $<0,01$ & $<0,01$ & 0,573 & $<0,01$ & $<0,01$ \\
\hline
\end{tabular}

Legenda: Taxa de Cobertura Qualificada de Cadastros (TCQC), Taxa de Atualização Cadastral (TAC), Taxa de Acompanhamento da Agenda de Saúde (TAAS), Taxa de Acompanhamento da Frequência Escolar (TAFE).

Fonte: Elaboração dos autores (2017) a partir de dados do MDS de dezembro 2012

A relação negativa entre o desempenho do IGD e de seus componentes e o tamanho dos municípios pode ser atribuída ao fato de que parte dos processos elementares do Programa envolvem cadastro, atualização e monitoramento de condicionalidades, e que quanto mais dispersas essas famílias estiverem em uma dada área geográfica mais dificuldades haverá para a gestão do Programa. O agravante é a gestão centralizada em alguns pontos (Cadastro Único e Secretarias de Assistência Social, Saúde e Educação) e a articulação deficitária com a rede assistencial (equipes de ESF, escolas e CRAS). Assim, quanto maior o território mais dificuldades na localização e acompanhamento dos beneficiários em bolsões de pobrezas, pois nesses bolsões costumam haver áreas sem cobertura de rede assistencial e que são de difícil acesso físico.

Outro determinante associado ao tamanho dos municípios é o número de beneficiários daquela localidade. Pode haver municípios com uma ampla área territorial e uma pequena quantidade de beneficiários, assim como municípios de menor área territorial e uma significativa quantidade de beneficiários em relação à população geral. Isso se deve ao perfil de elegibilidade do Programa que considera a renda da população e não cotas proporcionais à população total. 
A densidade de beneficiários nas capitais e regiões brasileiras (famílias por $\mathrm{km}^{2}$ ) está evidenciada na Tabela 4 . As capitais possuem ainda uma densidade de beneficiários muito maior que os associados às regiões, sugerindo que nessas localidades, além da área territorial, a dificuldade de gestão pode ser agravada pelo número de beneficiários. No Nordeste, região de maior concentração de beneficiários do programa no país, a média da densidade de beneficiários é 25 vezes maior do que a média dos municípios da região.

Tabela 4

Densidade Populacional de Beneficiários na Localidade (Famílias por $\mathbf{k m}^{2}$ ) nas Regiões Brasileiras em Dezembro de 2012

\begin{tabular}{|c|c|c|c|c|c|c|}
\hline \multicolumn{7}{|c|}{ REGIÕES DO PAÍS } \\
\hline MUNICÍPIOS DAS REGIÕES & NO & NE & $\mathrm{CO}$ & SE & SU & BRA \\
\hline $\begin{array}{c}\text { Densidade Populacional de Beneficiários } \\
\text { na localidade (famílias por } \mathrm{km}^{2} \text { ) }\end{array}$ & 2,31 & 11,45 & 1,79 & 8,50 & 2,63 & 7,14 \\
\hline \multicolumn{7}{|c|}{ MÉDIA DAS CAPITAIS DAS REGIÕES } \\
\hline CAPITAIS DAS REGIÕES & NO & NE & $\mathrm{CO}$ & SE & SU & BRA \\
\hline $\begin{array}{c}\text { Densidade Populacional de Beneficiários } \\
\text { na localidade (famílias por } \mathrm{Km}^{2} \text { ) }\end{array}$ & 15,45 & 293,80 & 16,61 & 169,04 & 63,26 & 141,10 \\
\hline
\end{tabular}

Legenda: Taxa de Cobertura Qualificada de Cadastros (TCQC), Taxa de Atualização Cadastral (TAC), Taxa de Acompanhamento da Agenda de Saúde (TAAS), Taxa de Acompanhamento da Frequência Escolar (TAFE).

Fonte: Elaboração dos autores (2017) a partir dos dados do MDS de dezembro 2012

Pressupõe-se que, quanto mais denso é o município, maior será a demanda de beneficiários para essa localidade, o que torna mais difícil a localização das famílias e, por consequência, seu acompanhamento. $\mathrm{O}$ número de beneficiários é determinado pelas cotas estipuladas pelo IBGE que indica o percentual de pessoas pobres e extremamente pobres naquela localidade. Municípios podem ter muitos pobres e não possuir uma estrutura de implementação de Programa. Pode haver ineficiência de agentes-chaves (Cadastro único e Secretarias) e insuficiência de rede assistencial para receber a demanda estimulada pelos processos de cadastro, atualização e acompanhamento das condicionalidades. Dessa forma, a relação negativa apontada entre a densidade das famílias nas localidades e o IGD-M e seus subcomponentes, apontada pela Tabela 5, pode dever-se a uma incompatibilidade entre o estimulo aos serviços básicos que a localidade não dispõe de meios para suprir. 
Tabela 5

Correlação do IGD-M e seus Subcomponentes e a Densidade Populacional de Beneficiários na Localidade (Famílias por $\mathrm{km}^{2}$ ) dos Municípios Brasileiros em Dezembro 2012

\begin{tabular}{c|c|c|c|c|c}
\hline \multicolumn{7}{c}{ CORRELAÇÃO DE PEARSON } \\
\hline & IGD fator $\mathbf{1}$ & TAFE & TAAS & TCQC & TAC \\
\hline $\begin{array}{c}\text { Densidade das famílias } \\
\text { (família por km²) }\end{array}$ & -0.140 & -0.036 & -0.154 & -0.044 & -0.030 \\
\hline \multicolumn{7}{c}{ Valor-p } \\
\hline $\begin{array}{c}\text { Densidade das famílias } \\
\left.\text { (família por } \mathrm{km}^{2}\right)\end{array}$ & $<\mathbf{0 . 0 1}$ & $<\mathbf{0 . 0 1}$ & $<0.01$ & $<0.01$ & $<0.05$ \\
\hline
\end{tabular}

Legenda: Taxa de Cobertura Qualificada de Cadastros (TCQC), Taxa de Atualização Cadastral (TAC), Taxa de Acompanhamento da Agenda de Saúde (TAAS), Taxa de Acompanhamento da Frequência Escolar (TAFE).

Fonte: Elaboração dos autores (2017) através dos dados do MDS de dezembro 2012

Observa-se que as subtaxas estabelecem uma correlação negativa com a densidade das famílias nos municípios. Ou seja, os municípios com maior densidade de beneficiários têm dificuldade para suprir as redes de serviços básicos: assistência social, educação e saúde. Pizzolato (2014) mostra que municípios menores e com menor número de beneficiários possuem melhor desempenho, pois há uma maior proximidade da população com a prefeitura e, assim, os gestores podem fiscalizar melhor a situação das famílias, cadastrando e atualizando corretamente os cadastros, além de analisarem se as condicionalidades em saúde e educação estão sendo cumpridas. Em pequenos municípios também é mais fácil divulgar informações do PBF, de cursos de capacitação e geração de renda, ampliando assim o cumprimento das condicionalidades do Programa.

As capitais brasileiras apresentam diferenças de desempenho por serem regiões predominantemente urbanas. Conforme indica a Tabela 6 , localidades com maior percentual de população urbana têm uma relação negativa com bons indicadores do IGD e seus subcomponentes.

Há diferenças significativas entre a pobreza urbana e a pobreza rural. Uma das possíveis causas disto é que os beneficiários urbanos, em comparação com beneficiários rurais, têm menor estabilidade de permanência em um domicilio devido à mudança de ocupações informais e arranjos familiares mais complexos, com membros da mesma família residindo em diferentes domicílios. 
Distribuição Espacial do Desempenho do Programa Bolsa Família

Tabela 6

Correlação do IGD-M e seus Subcomponentes e o Percentual de População Urbana dos Municípios Brasileiros em 2012

\begin{tabular}{l|c|c|c|c|c}
\hline \multicolumn{7}{c}{ CORRELAÇÃO DE PEARSON } \\
\hline & IGD fator $\mathbf{1}$ & TAFE & TAAS & TCQC & TAC \\
Percentual de População Urbana & -0.270 & -0.060 & -0.237 & -0.033 & -0.199 \\
\hline \multicolumn{7}{|c|}{ Valor-p } \\
\hline & IGD fator $\mathbf{1}$ & TAFE & TAAS & TCQC & TAC \\
Percentual de População Urbana & $<\mathbf{0 . 0 1}$ & $<\mathbf{0 . 0 1}$ & $<\mathbf{0 . 0 1}$ & $<\mathbf{0 . 0 1}$ & $<\mathbf{0 . 0 1}$ \\
\hline
\end{tabular}

Legenda: Taxa de Cobertura Qualificada de Cadastros (TCQC), Taxa de Atualização Cadastral (TAC), Taxa de Acompanhamento da Agenda de Saúde (TAAS), Taxa de Acompanhamento da Frequência Escolar (TAFE)

Fonte: Elaboração dos autores (2017) através dos dados do MDS de dezembro 2012

A diferença entre pobreza urbana e rural é mais complexa que a distinção de pobreza absoluta e pobreza relativa. Segundo Rocha (2013) é intuitivamente percebido que o custo de vida para todos, portanto também para os mais pobres, tende a ser mais elevado em áreas metropolitanas do que nas áreas urbanas, e nestas mais do que nas rurais. Considera-se também que assim como o meio rural pode ser mais pobre, também há famílias em boas condições de vida, dada a possibilidade de exercer diversas atividades agrícolas e pecuárias, assim como existem áreas marginalizadas em periferias metropolitanas, embora haja maior concentração de renda financeira no meio urbano, sobretudo em áreas marginalizadas das periferias metropolitanas.

Considerando estes aspectos, a renda não distingue por si só entre tipos de pobreza, pois uma pessoa pode ser enquadrada no perfil de renda "baixo" e ter condições de vida melhores que outra que dispõe de uma renda satisfatória em um lugar onde o custo de vida é mais alto. Um fenômeno tão complexo como a pobreza é difícil de mensurar. A definição de parâmetros pode incluir vieses e ser tendenciosa em virtude da própria heterogeneidade do problema, e isso cria dificuldades para comparar critérios ditos universais em circunstâncias polarizadas como a pobreza rural e a pobreza urbana (Rocha, 2013). Em síntese, os condicionantes apresentados indicam que a implementação do Programa se torna mais complexa em áreas com maior faixa territorial, com maior densidade de beneficiários e em localidades urbanas. As correlações mais fortes estão ligadas aos subindicadores das condicionalidades implementadas pelas redes de serviços básicos já preexistentes nessas localidades. Ou seja, a gestão do Programa é mais com- 
plexa em áreas metropolitanas e capitais, e uma das causas disso pode estar na ser sua fraca rede assistencial que não comporta as grandes demandas do Programa. .

Pastorini (2006) aponta que as políticas focalizadas e centralizadas em governos nacionais tendem a ser frágeis quando se sustentam na estrutura preexistente e deficitária das políticas universais, que pretendem ser descentralizadas em governos locais, mas contêm grandes lacunas de assistência, principalmente no que diz respeito à disponibilidade de acesso equitativo para os mais pobres.

As ações do PBF são direcionadas a uma parcela da população especifica (os extremamente pobres principalmente), pressupondo-se que há regiões com maior concentração de famílias beneficiárias do que outras devido à concentração espacial da pobreza, que é acentuada no Brasil. O crescimento da necessidade de recursos para assistência aos beneficiários não é acompanhado pela ampliação da rede de assistência à saúde e educação nessas localidades, ainda que se espere que a participação no Programa pressione pela expansão de atendimentos nesses lugares. Dessa forma, as ações de saúde e educação não alcançam o mesmo ritmo de expansão do PBF.

O PBF funciona acoplado às redes de serviços básicos já existentes. Portanto, as características das redes podem ter implicações nas atividades do Programa. No intuito de verificar como essas redes são utilizadas analisamos o grau de demanda relativa de beneficiários do Programa na rede de serviços básicos nos municípios brasileiros e suas regiões, conforme apresenta a Tabela 7.

Demandas maiores nas médias das famílias beneficiárias das capitais foram constatadas nos três indicadores estudados. Representada pelo número de equipes do ESF, a rede de saúde foi a que apresentou menor diferença de demanda entre a média nacional (331,51 famílias do Programa por equipe do PSF) e a média das capitais (369,3 famílias do Programa por equipe do PSF). Entre as regiões, a que apresentou maior demanda de famílias por equipe foi a Região Nordeste, com 454,00 famílias participantes por ESF; nas médias das capitais, a mais alta pertence à mesma região, sendo 502,50 famílias por equipes do ESF.

A rede de assistência social, indicada neste estudo pela somatória de CRAS e CREAS, teve uma demanda média nas capitais três vezes maior que na média das regiões. Entre as regiões, o maior valor da taxa 
Distribuição Espacial do Desempenho do Programa Bolsa Família

Tabela 7

Número de Famílias Beneficiárias do PBF por Unidade do PSF, CREAS e CRAS e

Escolas de Ensino Fundamental em Dezembro de 2012

\begin{tabular}{|c|c|c|c|c|c|c|}
\hline \multicolumn{7}{|c|}{ MÉDIA DOS MUNICÍPIOS DAS REGIÕES } \\
\begin{tabular}{|c|c|c|c|c|c|c|}
\hline MUNICÍPIOS DAS REGIÕES & NO & NE & CO & SE & SU & BRA \\
\hline $\begin{array}{c}\text { Número de Famílias por } \\
\text { Unidade do PSF }\end{array}$ & 415,84 & 454,00 & 283,00 & 260,21 & 203.57 & 331,51 \\
\hline $\begin{array}{c}\text { Número de Famílias por } \\
\text { CRAS/CREAS }\end{array}$ & 1602,34 & 1773,97 & 687,07 & 766,97 & 475,46 & 1098,78 \\
\hline $\begin{array}{c}\text { Número de Famílias por escola } \\
\text { de ensino fundamental }\end{array}$ & 87,32 & 113,58 & 111,09 & 100,40 & 63,29 & 96,57 \\
\hline $\begin{array}{c}\text { MÉDIA DAS CAPITAIS DAS REGIÕES } \\
\text { CAPITAIS DAS REGIÕES }\end{array}$ & NO & NE & CO & SE & SU & BRA \\
\hline $\begin{array}{c}\text { Número de Famílias por } \\
\text { Unidade do PSF }\end{array}$ & 467,13 & 502,50 & 215,57 & 161,31 & 172,22 & 369,3 \\
\hline $\begin{array}{c}\text { Número de Famílias por } \\
\text { CRAS/CREAS }\end{array}$ & 3545,28 & 5270,23 & 1491,17 & 2337,76 & 830,44 & 3406,13 \\
\hline $\begin{array}{c}\text { Número de Famílias por escola } \\
\text { de ensino fundamental }\end{array}$ & 133,77 & 171,72 & 94,50 & 97,34 & 78,07 & 130,3 \\
\hline
\end{tabular}
\end{tabular}

Legenda: Taxa de Cobertura Qualificada de Cadastros (TCQC), Taxa de Atualização Cadastral (TAC), Taxa de Acompanhamento da Agenda de Saúde (TAAS), Taxa de Acompanhamento da Frequência Escolar (TAFE).

Fonte: Elaboração dos autores (2017) a partir dos dados do MDS de dezembro 2012.

foi observado na Região Nordeste, com 1773,97 famílias por Centro de Referência. Nas médias das capitais, o maior valor de proporção ficou também nessa região, 5270,23 famílias por CRAS/CREAS. Esse número chega a ser mais de seis vezes superior à demanda relativa de beneficiários nas capitais do sul do país.

Quanto à rede de escolas públicas de ensino fundamental, a demanda das capitais em relação à média das regiões chega a ser $40 \%$ maior. Entre as regiões, o Nordeste apresenta a maior demanda relativa: 113,58 famílias por escolas de ensino fundamental. Tal situação se reflete nas médias das capitais que possuem a maior demanda relativa, com 171,72 famílias por escola de ensino fundamental.

Conforme descreve a Tabela 8, este grupo de variáveis indica de modo geral que o menor aparelhamento social da rede assistencial de serviços básicos tem influência negativa na gestão do PBF em estados e municípios. 
Fábio R. Araújo, Maria A.D. Araújo, Fábia J.V. Souza, Iris L.P. Gurgel, e Anna C.C. Gomes

Tabela 8

Correlação do IGD-M e seus Subcomponentes e o Número de Famílias Beneficiárias do PBF por Unidade do PSF, CREAS e CRAS e Escolas de Ensino Fundamental em 2012

\begin{tabular}{c|c|c|c|c|c}
\hline \multicolumn{7}{c}{ CORRELAÇÃO DE PEARSON } \\
\hline & IGD fator 1 & TAFE & TAAS & TCQC & TAC \\
\hline FAMILIAS/ESF & 0,053 & -0.13 & -0.076 & 0.127 & 0.173 \\
\hline FAMILIAS/CRAS & $-0,03$ & -0.71 & -0.107 & 0.102 & 0.164 \\
\hline FAMILIAS/ESCOLAS & 0,049 & -0.22 & -0.28 & 0,142 & 0.083 \\
\hline \multicolumn{7}{|c|}{ Valor-p } \\
\hline FAMILIAS/ESF & IGD fator 1 & TAFE & TAAS & TCQC & TAC \\
\hline FAMILIAS/CRAS & 0.01 & 0.013 & $<0.01$ & $<0.01$ & $<\mathbf{0 . 0 1}$ \\
\hline FAMILIAS/ESCOLAS & $<\mathbf{0 . 0 1}$ & $\mathbf{0 . 0 9 0}$ & $<\mathbf{0 . 0 5}$ & $<\mathbf{0 . 0 1}$ & $<\mathbf{0 . 0 1}$ \\
\hline
\end{tabular}

Legenda: Taxa de Cobertura Qualificada de Cadastros (TCQC), Taxa de Atualização Cadastral (TAC), Taxa de Acompanhamento da Agenda de Saúde (TAAS), Taxa de Acompanhamento da Frequência Escolar (TAFE).

Fonte: Elaboração dos autores (2017) a partir dos dados do MDS de dezembro de 2012

O acompanhamento das condicionalidades da saúde é feito faz na Atenção Básica do Sistema Único de Saúde, executada pela Equipe Saúde da Família. Os resultados indicam que localidades com um menor número relativo dessas equipes por beneficiários revelam menor desempenho nas condicionalidades da saúde (TAAS) com significância estatística, e da educação (TAFE) sem significância estatística.

A rede de assistência social, além do Cadastro Único, é representada pelos CRAS e CREAS. Em tese, o número desses equipamentos sociais por número de beneficiários implica em uma gestão mais descentralizada nas localidades, portanto, quando em menor número diminuem a eficácia nos serviços básicos do Programa. Os dados indicam uma relação negativa entre o número de beneficiários por unidade de CRAS e CREAS e os componentes ligados às condicionalidades (TAAS e TAFE).

Os resultados apontam que um menor número de escolas por beneficiários implica um cumprimento menos efetivo das condicionalidades da saúde que se expressa na TAAS (com correlação significativa estatisticamente). O fato pode decorrer de uma maior estabilidade das famílias quando permanecem com filhos matriculados na rede escolar.

As subtaxas TAC e TCQC tiveram correlações positivas com número de famílias beneficiárias do PBF por Unidade do PSF, CREAS e CRAS e 
Escolas de ensino fundamental, o que pode ser entendido pelo fato de essas demandas por equipamentos públicos estarem mais ligadas às condicionalidades do que aos processos de Cobertura Qualificada de Cadastros (TCQC) e Taxa de Atualização Cadastral (TAC) que ocorrem no Cadastro Único.

Foram identificadas correlações positivas com significância estatística entre o fator de operação do IGD e as taxas de número de famílias beneficiárias do PBF por Unidade do PSF e escolas de ensino fundamental. Tal relação pode decorrer do Fator de operação ser constituído por 50\% dos valores de TCQC e TAC e, pelos motivos anteriormente citados, não serem dependentes da rede dos serviços analisados nestas relações e sim da presença do Cadastro Único e das Secretárias Municipais de Assistência Social.

As correlações permitem interpretar que as variáveis sócio-demográficas (urbanização, densidade populacional do território e área territorial) possuem maior poder explicativo do fator de operação do IGD do que de outros fatores estudados, os quais possuem relação, mas não têm poder explicativo. Para verificar quanto estas variáveis explicam o IGD, foi construído um Modelo de regressão multivariada descrito na Tabela 9.

Tabela 9

Modelo de Regressão Multivariada dos Fatores Explicativos do Fator de Operação do IGD-M nos Municípios Brasileiros em 2012

\begin{tabular}{l|c|c|c|c}
\hline \multicolumn{4}{c}{ VARIÁVEL DEPENDENTE: IGD- FATOR DE OPERAÇÃO } \\
\hline Variáveis independentes & Coeficiente & Std. Erro & t-Statistic & Prob \\
\hline C & 0,906304 & 0,002278 & 397.9267 & 0.0000 \\
\hline \% de Urbanização (2010) & -0.000683 & $3.56 \mathrm{E}-05$ & -19.19074 & 0.0000 \\
\hline Densidade de famílias beneficiarias & -0.000192 & $4.11 \mathrm{E}-05$ & -4.669239 & 0.000 \\
\hline Área territorial & $-9.41-\mathrm{E} 07$ & $1.58 \mathrm{E}-07$ & -5.957674 & 0.000 \\
\hline
\end{tabular}

R- squared: 0.089329

Número de municípios analisado:5560

O modelo atribui maior poder explicativo da área territorial ao IGD-M em detrimento do percentual de urbanização e da densidade populacional das famílias beneficiárias (que também são explicativas, mas em menor expressão). Por fim, compreende-se que essas variáveis explicam em parte o IGD-M e, portanto, determinam o desempenho do Programa Bolsa Família. O uso do teste de White decorreu da heterocedasticidade presente no modelo, conforme recomendam Corrar, Paulo e Dias Filho (2007).

DADOS - Revista de Ciências Sociais, Rio de Janeiro, vol. 61, nº 3, 2018 
Compreende-se, portanto, a gestão do PBF como dinâmica, e mais desafiante em áreas territoriais mais extensas, com maior concentração de beneficiários e em zonas urbanas. Um conceito extremamente valorizado atrelado ao Programa é o de equidade, principalmente nas condicionalidades e programas complementares que pretendem inserir o público privado de acesso nessas iniciativas. Historicamente, o acesso aos serviços é dificultado para o público mais pobre por inúmeros fatores: localidades com maior densidade populacional, periferias em franca expansão, aumento da complexidade das assistências, nível de escolaridade dos usuários entre outros.

O Programa das Nações Unidas (1997) classifica pobreza como a falta de acesso e de recursos (não apenas financeiros) que permitam o atendimento às necessidades básicas. Compreende-se que o acesso a serviços de modo ativo e equitativo faz com que estes indivíduos sejam respeitados como cidadãos. Testa et al. (2013) revela que a capacidade de acesso aos serviços pode ser afetada substancialmente pela idade, sendo o acesso dificultado para determinados grupos (idosos, gestantes, portadores de necessidades especiais), pela localização nas áreas urbanas com alta densidade populacional e com rede saturada de serviços e características epidemiológicas.

Os dados deste estudo permitem constatar que o gerenciamento do PBF em regiões metropolitanas, em especial nas capitais, é mais difícil, entre outros motivos, pela alta concentração de beneficiários e baixa capacidade de gestão e rede de serviços básicos dessas localidades. Veloso et al. (2011) indica que a diferença entre a arrecadação fiscal e o contingente populacional dos municípios agrava as disparidades entre as localidades, pois os municípios que geram maior receita própria também são aqueles que reúnem o maior contingente populacional, detentores de grandes demandas em termos de políticas públicas, enquanto que os municípios que não possuem base econômica desenvolvida são mais dependentes de recursos provenientes das transferências da União e possuem menor contingente populacional. O resultado da conjugação desses fatores é uma acentuada assimetria na disponibilidade de recursos por habitante, a qual se manifesta em diferentes formas de assistência por parte de políticas sociais. Os autores indicam que essa assimetria gera uma separação entre as tendências de concentração espacial dos recursos e de concentração das demandas por esses recursos. Veloso et al. (2011) indica que a descentralização fiscal tende a favorecer os municípios menores, porém a demanda tende a se concentrar nos centros urbanos, devido ao ritmo de urbanização e à metro- 
polização da pobreza, combinados com maiores custos de solução dos problemas enfrentados que exigem maior complexidade tecnológica. Dessa forma, a atenção do Estado deveria voltar-se com prioridade para as populações menos favorecidas economicamente, localizadas nos centros urbanos, o que não é observado no atual sistema de transferências.

Gomes e Mac Downell (2000) apontam, também nesse sentido: os centros urbanos são prejudicados nessa divisão fiscal enquanto os pequenos municípios têm mais receita por habitantes que todos os demais. Ou seja, a grande dificuldade de recursos não se concentra nos municípios pequenos, mas nas grandes cidades onde as políticas são mais difíceis de operar. Os autores sustentam que, no Brasil como um todo, municípios muito pequenos, especialmente os do grupo de até 5 mil habitantes, classificados pelo IBGE como micro municípios, dispõem de mais recursos financeiros per capita do que quaisquer outros.

Ou seja, o arcabouço constitucional favorece pequenos municípios, que acabam possuindo maior renda per capita de recursos oriundos de outras localidades e melhor capacidade de gerenciar políticas sociais pela pequena demanda sob sua área de abrangência. Já nas áreas metropolitanas a situação se inverte, e estas passam a concentrar as grandes demandas das políticas sociais e há falta de recursos suficientes para administrá-las considerando a magnitude da pobreza na localidade.

Bichir (2011) mostra que as áreas urbanas representaram desafios para a implementação de programas de transferência de renda por serem áreas heterogêneas que impõem a necessidade de levar em conta a dimensão espacial da pobreza e a focalização em áreas de maior concentração de beneficiários.

Licio (2004) afirma que, para que o Bolsa Família se concretize, faz-se necessário incentivar a construção de redes e a ação regionalizada, principalmente entre municípios das regiões metropolitanas onde a questão da inclusão social exige, ainda mais, soluções coordenadas. Uma sugestão seria a adoção de consórcios que reunissem os recursos físicos e financeiros dos respectivos municípios para a gestão coordenada do Programa.

\section{CONSIDERAÇÕES FINAIS}

A padronização foi necessária, principalmente no início, para que o PBF se nacionalizasse. Entretanto, mais de uma década após sua cria- 
ção, nota-se que a homogeneização de condutas frente às significativas disparidades de ordem econômica, social, política e de capacidade fiscal e administrativa entre os entes federativos brasileiros é pouco estratégica para o desempenho do Programa.

Além das particularidades de cada nível de governo no Brasil observam-se diferenças significativas entre entes de um mesmo nível. Os estados brasileiros, por exemplo, mostram claras distinções no tocante aos indicadores de pobreza e cobertura de serviços para cidadania. Dentro das próprias regiões existem contrastes que são fruto da determinação histórica da formação nacional. O resultado desse cenário são diferenças significativas também da capacidade estatal desses entes para implementarem suas políticas e, por consequência, na obtenção de desempenho das políticas.

Ao analisar a infraestrutura (redes de serviços assistenciais, recursos humanos, financeiros e tecnológicos adequados e disponíveis) para a condução das ações da gestão do $\mathrm{PBF}$, nos governos subnacionais, observa-se que estes fatores têm repercussões significativas para o desempenho do programa. A deficitária cobertura e qualidade de serviços básicos para cidadania (estruturação mínima do SUAS em suas unidades de atendimento CRAS e CREAS, a cobertura das equipes de PSF e ACS na saúde e a estrutura da rede educacional) resultaram em adaptações dos propósitos do Programa, tornando-o limitado para alcançar melhores indicadores, mesmo depois de mais de uma década da implementação. A maior dificuldade de implementação encontra-se em municípios populosos, em áreas urbanas e com alta densidade de famílias beneficiárias por localidade.

Ressalta-se que as condicionalidades do PBF não manifestam nada de diferente dos mais elementares procedimentos para o alcance de direitos sociais previstos na Constituição. $\mathrm{O}$ alcance parcial desses procedimentos para a parcela mais pobre da população brasileira (leia-se, aquela que não consegue optar por assistência privada) é revelador do nível de alcance que as principais políticas sociais brasileiras possuem nos governos locais.

Recebido para publicação em 16 de julho de 2016 Reapresentado em 17 de maio de 2017

Reapresentado em 8 de abril de 2018

Aprovado para publicação em 1 de novembro de 2018 


\section{NOTAS}

1. Dados da Secretária Nacional de Renda e Cidadania (SENARC) do Ministério do Desenvolvimento Social e Combate a Fome (MDS) citados por Neri e Campelo (2013)

2. Afonso (2006) aponta que o conceito de governos locais tende a designar sobretudo os municípios no Brasil. Contudo, o autor esclarece que não apenas os governos municipais são abrangidos por esta classificação, governos locais também são os estaduais. Adotamos dessa forma o conceito de governos locais para nos referirmos a municípios e/ou a estados.

3. Considera-se como cadastro válido atualizado aquele que atende integralmente aos seguintes requisitos: a) ter todos os campos obrigatórios do Formulário Principal de Cadastramento preenchidos integralmente para todos os componentes da família; $\mathrm{e}$ b) apresentar, no que se refere ao Responsável pela Unidade Familiar - RF, o registro do Cadastro de Pessoa Física - CPF e/ou título eleitoral, com exceção de famílias indígenas e quilombolas, cujo RF poderá apresentar qualquer outro documento de identidade previsto no Formulário de Cadastramento (Ministério de Desenvolvimento Social e Combate à Fome, 2012).

4. Taxa de Acompanhamento da Frequência Escolar (TAFE); Taxa de Acompanhamento da Agenda de Saúde (TAAS); Taxa de Atualização Cadastral (TAC); e Taxa de Cobertura Qualificada de Cadastros (TCQC).

\section{REFERÊNCIAS BIBLIOGRÁFICAS}

AFONSO, José Roberto. (2006), Novos desafios à descentralização fiscal no Brasil: as políticas sociais e as de transferência de renda. Texto apresentado ao debate no XVIIISeminário Regional de Política Fiscal (CEPAL/ILPES).

ARAUJO, Fábio Resende et al. (2015). “Uma avaliação do Índice de Gestão Descentralizada do Programa Bolsa Família. " Revista de Administração Pública, vol. 2, no 49. pp. 367-393.

BICHIR, Renata Mirandola. (2011), Mecanismos federais de coordenação de políticas sociais e capacidades institucionais locais: o caso do Programa Bolsa Família. Tese (Doutorado em Ciência Política). Universidade do Estado do Rio de Janeiro. Rio de Janeiro.

CAMARGO, Camila Fracaro et al. (2013), "Perfil socioeconômico dos beneficiários do programa Bolsa Família: o que o Cadastro Único revela?", in: M. C. Neri e T. Campello (eds.) Programa Bolsa Família: Uma década de inclusão e cidadania, Brasília, IPEA, pp. 157-179.

CAMPELO, Tereza. (2013), "Uma década derrubando mitos e superando expectativas". in: M. C. Neri e T. Campello (eds.) Programa Bolsa Família: Uma década de inclusão e cidadania Brasília, IPEA, pp.14-24.

COBO, Barbara. (2012), Políticas focalizadas de transferência de renda: contextos e desafios. São Paulo, Cortez.

CORRAR, Luiz; PAULO, Edilson; DIAS FILHO, José Maria (2007) Análise Multivariada: para os cursos de Administração, Contábeis e Economia. São Paulo: Atlas. 
ESTRELLA, Juliana; RIBEIRO, Leandro. (2008), “Qualidade da gestão das condicionalidades do Programa Bolsa Família: uma discussão sobre o índice de gestão descentralizada. " Revista de Administração Pública, vol. 42, no 3, pp.351-367.

GOMES, Gustavo Maia; MACDOWELL, Maria Cristina.(2000) Descentralização política, federalismo fiscal e criação de municípios: o que é mau para o econômico nem sempre é bom para o social. Texto para Discussão, n. 706. Brasília, IPEA.

LICIO, Eliane. (2004), “A trajetória dos programas de transferência de renda no Brasil: o impacto da variável federativa." Revista do Serviço Público. vol. 3, no 55, pp.37-59.

MINISTÉRIO DE DESENVOLVIMENTO SOCIAL E COMBATE À FOME. (2012), Caderno do IGD-M: Informativo sobre o Índice de Gestão Descentralizada Municipal do Programa Bolsa Família. Secretaria Nacional de Renda da Cidadania. Brasília.

MINISTÉRIO DE DESENVOLVIMENTO SOCIAL E COMBATE À FOME. (2012), Caderno do IGD-E: Informativo sobre o Índice de Gestão Descentralizada Estadual do Programa Bolsa Família. Secretaria Nacional de Renda da Cidadania. Brasília.

MONTEIRO, Doraliza Auxiliadora. (2008), Alocação de recursos e eficiência na gestão do Programa Bolsa Família. Dissertação (Mestrado em Administração). Universidade Federal de Viçosa. Viçosa.

MONTEIRO, Doraliza Auxiliadora. FERREIRA, Marco Aurélio Marques. TEXEIRA, Karla Maria Daminao. (2009), "Determinantes da Gestão do Programa Bolsa Família: análise do índice de gestão descentralizada em Minas Gerais." Saúde Sociedade. vol.18, no 2, pp.214-226.

MONTEIRO, Doraliza Auxiliadora; SILVA, Ambrozina de Abreu; RIBEIRO, Elizabeth Matos. (2014), "Avaliação da Gestão do Programa Bolsa Família na Bahia." Revista Interdisciplinar de Gestão Social, vol. 3 no 3, pp.259.

NERI, Marcelo Côrtes; CAMPELLO, Tereza. (eds.). (2013), Programa Bolsa Família: Uma década de inclusão e cidadania. Brasília, IPEA.

PASTORINI, Alejandra. (2006) "Assistencialização da proteção social e os programas de combate a pobreza no Brasil." Revista Ser Social. vol.1, no 18, pp. 253-284

PEDROSO, Marcel de Moraes; DU PIN CALMON, Paulo Carlos; BANDEIRA, Ludmila Ferreira. (2009), "O uso da Análise Envoltória de Dados para avaliação da gestão do Programa Bolsa-Família." Comunicação em. Ciências da Saúde. vol.1, no 20, pp. 37-44.

PIZZOLATO, Bruna. (2014), Desempenho dos municípios na gestão do Programa Bolsa Família: o impacto das características da burocracia local. Dissertação (Mestrado em Administração Pública). Escola de Administração de Empresas de São Paulo. São Paulo.

PROGRAMA DAS NAÇÕES UNIDAS PARA O DESENVOLVIMENTO. (1997), Glossário da pobreza e desenvolvimento humano. In: PNUD. Relatório do desenvolvimento humano. Brasília.

ROCHA, Sônia.(2013), Transferência de renda: o fim da pobreza? Rio de Janeiro, Elsevier.

TESTA, Maurício Gregianin et al. (2013). Análise da contribuição do Programa Bolsa Família para o enfrentamento da pobreza e a autonomia dos sujeitos beneficiários. Revista de Administração Pública, vol. 47, no 6, pp.1519-1541.

VELOSO, João Francisco Alves et al. (2011), “Uma visão inicial dos subsistemas da gestão municipal.", in: J. F. A. Veloso (eds.). Gestão municipal no Brasil: um retrato das prefeituras. Brasília, Ipea, pp. 11-39.

DADOS - Revista de Ciências Sociais, Rio de Janeiro, vol. 61, n 3, 2018 
RESUMO

Distribuição Espacial do Desempenho do Programa Bolsa Família: um Estudo à Luz do IGD-M

O artigo analisa os condicionantes da distribuição espacial do desempenho do Programa Bolsa Família (PBF) à luz do Índice de Gestão Descentralizada (IGD-M) nos municípios brasileiros. Como procedimento metodológico delimitou-se como variável dependente o IGD-M e as variáveis independentes alguns condicionantes da gestão do PBF em nível municipal (área territorial em $\mathrm{Km}^{2}$; percentual de população urbana; densidade famílias por $\mathrm{Km}^{2}$; número de Famílias por Unidade do Programa Saúde da Família, Centro de Referência da Assistência Social e Escola de ensino fundamental). Como resultados são comprovadas as hipóteses de que o desempenho do programa é inversamente proporcional ao tamanho dos municípios, percentual de urbanização e concentração de famílias beneficiárias por $\mathrm{Km}^{2}$. Além disso, a deficitária cobertura e serviços básicos para a cidadania nas áreas de Assistência social, Saúde e Educação implicam em menor desempenho das condicionalidades do programa. Conforme o modelo de regressão múltipla estimado para explicar o desempenho do IGD nos municípios brasileiros as variáveis explicativas mais importantes foram área territorial em $\mathrm{Km}^{2}$, percentual de população urbana e densidade famílias por $\mathrm{Km}^{2}$. Conclui-se que o alcance parcial desses procedimentos para a parcela mais pobre da população brasileira é revelador do nível de alcance e descentralização que as principais políticas sociais brasileiras possuem nos governos municipais.

Palavras-chave: Descentralização de políticas, Implementação de políticas, Programa Bolsa Família, Políticas Sociais, Governos locais.

\section{ABSTRACT \\ Spatial Distribution of the Performance of the Bolsa Familia Program: a Study using the IGD-M}

The article analyzes the determinants of the spatial distribution of the "Programa Bolsa Família" (PBF) performance using the Decentralized Management Index (IGD-M) for Brazilian municipalities. As a methodological procedure, the IGD-M was defined as the dependent variable and the independent variables were some determinants of PBF management at the municipal level (territorial area in $\mathrm{Km}^{2}$, percentage of urban population, density of families per $\mathrm{km}^{2}$, number of families per unit of Health Program Family Center, Social Assistance Reference Center, and Elementary School). 
The results run in favor of the hypotheses that the performance of the program is inversely proportional to the size of municipalities, percentage of urbanization and concentration of beneficiary families per $\mathrm{km}^{2}$. Also, the lack of coverage and basic services for citizenship in the areas of Social Assistance, Education and Health imply a lower performance of the conditionalities of the program. According to a multiple regression model estimated to explain the performance of the IGD in the Brazilian municipalities, the most important explanatory variables are: territorial area in $\mathrm{Km}^{2}$, percentage of urban population and density of families per $\mathrm{km}^{2}$. We conclude that the partial reach of these procedures for the poorest part of the Brazilian population is revealing of the level of reach and decentralization that the main Brazilian social policies have in the municipal governments.

Keywords: Policy Decentralization, Policy Implementation, Family Grant Program (programa bolsa família), Social Policies, Local Governments

\section{RÉSUMÉ}

Distribution spatiale de la performance du Programme Bolsa Família : une étude à la lumière de IGD-M

L'article analyse la performance du Programme Bolsa Família (PBF) et son distribution spatiale à la lumière de l'Indice de Gestion Décentralisée (IGD-M) dans les municipalités brésiliennes. Tandis que procédure méthodologique, l'IGD-M est défini comme la variable dépendante et les variables indépendants son les déterminants de la gestion du FBP au niveau municipal (zone territoriale en $\mathrm{km}^{2}$, pourcentage de la population urbaine, densité de familles par $\mathrm{km}^{2}$, nombre de familles par unité de programme de santé Centre de Référence de la Famille, Centre de Référence de l'Assistance Sociale et l'existence des écoles primaires). En conséquence, l'hypothèse selon laquelle la performance du programme est inversement proportionnelle à la taille des municipalités, du pourcentage d'urbanisation et de la concentration de familles bénéficiaires par $\mathrm{km}^{2} \mathrm{c}^{\prime}$ est prouvée. D'autre coté, la couverture et de services de base déficitaire pour la citoyenneté dans les domaines de l'Assistance Sociale, de la Santé et de l'Éducation implique une performance inférieure des conditionnalités du programme. D'après le modèle de régression multiple estimé, les variables explicatives les plus importantes pour expliquer la performance de l'IGD dans les municipalités brésiliennes étaient la superficie territoriale en $\mathrm{km}^{2}$, le pourcentage de population urbaine et la densité de familles par $\mathrm{km}^{2}$. En conclusion, la portée partielle de ces 
procédures pour la partie la plus pauvre de la population brésilienne est révélatrice du niveau de portée et de décentralisation des principales politiques sociales brésiliennes dans les administrations municipales.

Mots-clés : décentralisation politique, mise en œuvre des politiques, Programme Bolsa Família, politiques sociales, gouvernements locaux.

\section{RESUMEN}

Distribución Espacial del Desempeño del Programa Bolsa Familia: un Estudio a la Luz del IGD-M

El artículo analiza los condicionantes de la distribución espacial del desempeño del Programa Bolsa Familia (PBF) a la luz del Índice de Gestión Descentralizada (IGD-M) en los municipios brasileños. Como procedimiento metodológico se delimitó como variable dependiente el IGD-M. Las variables independientes elegidas son algunos condicionantes de la gestión del PBF a nivel municipal: área territorial en $\mathrm{Km}^{2}$, porcentaje de población urbana; densidad familiar por $\mathrm{Km}^{2}$; cantidad de familias por Unidad del Programa Salud de la Familia, Centro de Referencia de la Asistencia Social y Escuela de enseñanza fundamental. Como resultados se demuestran las hipótesis de que el desempeño del programa es inversamente proporcional al tamaño de los municipios, porcentaje de urbanización y concentración de familias beneficiarias por $\mathrm{Km}^{2}$. Además, la deficitaria cobertura y servicios básicos para la ciudadanía en las áreas de Asistencia Social, Salud y Educación implican en peor desempeño de las condicionalidades del programa. Conforme al modelo de regresión múltiple estimado para explicar el desempeño del IGD en los municipios brasileños, las variables explicativas más importantes fueron: área territorial en $\mathrm{Km}^{2}$, porcentaje de población urbana y densidad de familias por $\mathrm{Km}^{2}$. Se concluye que el alcance parcial de esos procedimientos para la parcela más pobre de la población brasileña es revelador del nivel de alcance y descentralización que las principales políticas sociales brasileñas poseen en los gobiernos municipales.

Palavras-clave: descentralización de políticas; implementación de políticas; Programa Bolsa Familia; políticas sociales, gobiernos locales 


\section{ERRATA}

Na página 773, Onde se lia:

“http:/ / dx.doi.org/10.1590/001152582018159"

Leia-se:

“http:/ / dx.doi.org/10.1590/001152582018173"

DADOS - Revista de Ciências Sociais (2018), vol. 61, no 3: E3-E5

DADOS - Revista de Ciências Sociais, Rio de Janeiro, vol. 61, n 3, 2018 